\title{
IDENTIFICATION OF THE HONEYBEE SUBSPECIES FROM SOME ROMANIAN COUNTIES USING A SEMIAUTOMATIC SYSTEM FOR ANALYZING WINGS
}

\author{
Elena Buescu ${ }^{1}$, Maria Rodica Gurau ${ }^{2}$, Doina Danes ${ }^{3}$
}

\begin{abstract}
Morphometric analysis of honeybee wings can be used to discriminate between honeybee subspecies. The classic morphometric methods used to identify honeybee subspecies are time consuming while geometric morphometric analysis are proven to be more efficient and rapid for the identification of honeybee subspecies. Even if the geometric morphometric analysis involves several steps such as: obtaining the image of the honeybee wing, processing the wings image (settlement of the 19 points), classification and validation, in terms of consumed time, it takes less than classic morphometric methodes and it is easier to apply. The aim of this study was to identify honeybee subspecies from the Romanian South-Eastern area, using the geometric morphometric method. To accomplish this, the semiautomated French system ApiClass was used. This system allows us to identify the honeybee subspecies based on the wing's image of the Apis mellifera honeybee worker. The program is using the recent approaches of geometric morphometry and is analyzing the wing considering 19 points corresponding to the intersections of the main veins of the bee forewings. These coordinates are processed by the system before being analyzed after which the system returns the probability of the analyzed honeybee belonging to one of the honeybee subspecies from its reference system. The system has more than 5000 honeybee wing references off the main lines and honeybee subspecies. Using this system we analyzed samples from the counties of Braila, Buzau, Galati and Ilfov. Each sample was composed from wings of 20 honeybees. Most of the analyzed samples were identified as hybrids without being possible to specify the type or the level of the hybridization: only three samples were identified as being Apis mellifera carnica presenting a homology degree over $90 \%$.
\end{abstract}

UDC Classification: 638; DOI: http://dx.doi.org/10.12955/cbup.v6.1304

Keywords: morphometrics analysis, honeybee wing, Apis mellifera

\section{Introduction}

Honeybees live in different environments, such as mountainous, hilly areas, plains, dessert or wetlands and they are usually classified into about 30 subspecies (Leno da Silva, et al., 2015;Rinderer, 2008). Honeybees are grouped into four phylogenetic lines: A, C, M and O, each associated to a particular geographical area. Thus, the line A includes African breeds of Apis mellifera (Tropical Africa, North Africa): scutellata, adansonii, litorea, monticola, lamarckii, capensis, unicolor, yemenitica, sahariensis, intermissa, major. The line M (western and northern European Mediterranean group) includes the Apis mellifera: mellifera, iberica subspecies. The $\mathrm{O}$ line (the Middle East group) includes the Apis mellifera: anatolica, adami, cypria, syriaca, caucasica, meda and the line C (Central and Southern European Group) includes the Apis mellifera:sicula, ligustica,carnica (the Carniolian bee), macedonica, cecropia (Ruttner, 1988; Rinderer, 2008).

Every subspecies is adapted to a particular set of environmental characteristics (Ruttner,1988). Identification of Apis mellifera subspecies is useful for their protection but also for queen breeders, to preserve some breeding honeybee lines (Oleksa et al., 2015). Discrimination between the honeybee subspecies is useful for the conservation of their biodiversity, for monitoring of local honeybees and, also, for limiting the introduction of non-native subspecies. (Nawrocka et al., 2017). The methods designed to identify different honeybee subspecies rely on morphometric measurements of the entire honeybee body, including measures of some anatomic structures, the venation angles of the wing and the pigmentation. Wings are considered the most reliable morphological structure for insect identification; the evaluation of wing morphology being also recommended for the identification of honey bees. In the last years, the measurements of the fore wings have proven to be reliable for the $c^{1}$ lassification of honeybees (Leno da Silva et al., 2015). Even though differences between species are much more important than the intra-species ones, the intra-species variation is large enough to discriminate the bee subspecies. (MacLeod et al., 2007). Different methods were developed using automatic bee classification based on images of the wings, and geometric morphometrics proved to be a useful tool in terms of time efficiency and reliability of the results (Leno da Silva et al., 2015).

\footnotetext{
${ }^{1}$ University of Agronomical Science and Veterinary Medicine of Bucharest, Faculty of Veterinary Medicine, 105 Splaiul Independentei, $5^{\text {th }}$ District, Bucharest, Romania, helenabue2006@yahoo.com

${ }^{2}$ University of Agronomical Science and Veterinary Medicine of Bucharest, Faculty of Veterinary Medicine, 105 Splaiul Independentei, $5^{\text {th }}$ District, Bucharest, Romania, otelea_maria@yahoo.com

${ }^{3}$ University of Agronomical Science and Veterinary Medicine of Bucharest, Faculty of Veterinary Medicine, 105 Splaiul Independentei, $5^{\text {th }}$ District, Bucharest, Romania, danes.doina @ gmail.com
} 
Computerized methods using wing image are the most promising, reducing the number of dissected body parts and also avoiding the laborious preparation of sternites, mouthparts and legs (Nawrocka et al., 2017).

The automated identification of bee through wing images involves several steps such as: obtaining the image of the honeybee wing - high-quality wing images can be obtained using relatively inexpensive scanners (MacLeod et al., 2007), processing the wings image (settlement of the 19 points), and classification and validation, (Santana et al., 2014). Software packages were developed for the automated identification of the honeybee subspecies like: ABIS (Automated Bee Identification System) ((Leno da Silva, et al., 2015); ID-BEES; FABIS (Nawrocka, et al., 2017); DrawWing system (Tofilski, 2008); and the ApiClass system (Nawrocka et al., 2017; Baylac et al., 2008). The first three software are not usually available to the general public, but the last two software are (Nawrocka et al., 2017). The DrawWing system uses (Tofilski, 2008) the junctions of veins as landmarks for the geometrical morphometry (Oleksa et al., 2015). The position and numbering of each landmark was similar in the study of Gerula et al. (2009). The coordinates of the 19 vein junctions of the wings image were determined automatically using this software. (Oleksa et al., 2015).

\section{Data and methodology}

The aim of this study was to identify the honeybee subspecies from the Romanian South-Eastern area, using the geometric morphometric method. In this respect, the semiautomated French system ApiClass was used. This system allows us to identify the honeybee subspecies considering a picture of the wings' of the Apis mellifera honey bee worker. The program is using the recent advances of geometric morphometry and is analyzing the wing comparing 19 points corresponding of the intersections of the main veins of the bee forewings (Baylac et al., 2008).

These coordinates are processed before being analyzed by the system - and, then the system returns the probability of belonging to one of the honeybee subspecies from it reference directory. The system has more than 5000 honeybee wings from the honeybee main lines as well as subspecies. Using this system we analyzed samples from the counties Braila, Buzau, Galati and Ilfov. Each sample was composed from wings of - 20 honeybees.

Equipment and materials used were the slide scanner OpticFilm 7400 Plustek, glass blades, small glass blades, distilled water, pipettes, forceps, alcohol 70\%, Petri plates, collector tubes.
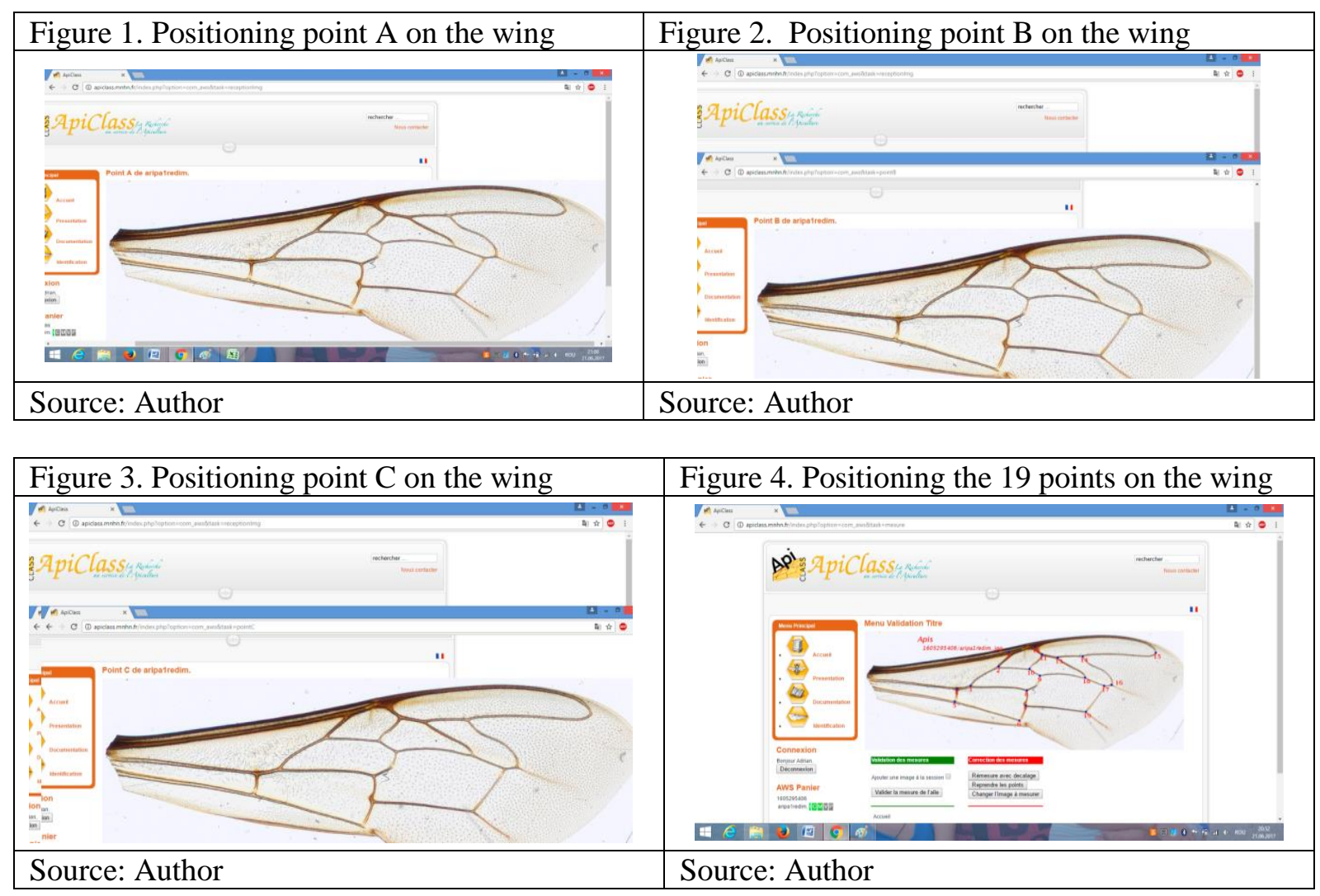
We scanned every honeybee forewing and the .jpg image was analyzed with the ApiClass system. After selecting the automatic measuring system, the wing image is inserted into the system. The next step takes place in three stages, respectively, positioning the A, B, C points on the wing.

After that, the ApiClass system processes the image and places the 19 points on the wing, validates and analyzes the image and compares it with the available database.

The analyzed honeybees came from the following counties/localities: Braila (Braila -2 samples, Lacu Sarat, Unirea, Boarca), Galati (Tulucesti - 3 samples, Cudalbi, Costi), Buzau (Smeeni- 3 samples, Cislau, Intorsura Buzaului), Ilfov (Cioflinceni).

\section{Results and Discussion}

Most of the analyzed samples were identified as hybrids without it being possible to specify the type or the level of the hybridization. Only three samples were identified as being Apis mellifera carnica presenting a homology degree over $90 \%$. To consider that a honeybee belongs to a particular subspecies of Apis mellifera the percentage must be over $90 \%$. After we analyse the wings with the Apiclass system the following was observed:

-in Buzau county, the sample from Cislau presented a homology degree over $90 \%$ with Apis mellifera carnica (19 wings from 20). The samples from Smeeni only one or three wings from 20 presented a homology degree over $90 \%$ with Apis mellifera carnica, the rest of the wings were identified as hybrids without it being possible to specify the type or the level of the hybridization (see Figure 5 to 9);

-in Braila county, the samples from Lacu Sarat (18 wings from 20) and one sample from Braila (15 wings from 20) presented a homology degree over $90 \%$ with Apis mellifera carnica, the rest of samples were hybrids (see Figure 10 to 14);

-in Ilfov county, just 2 wings from 20 were identified with a homology degree over $90 \%$ with Apis mellifera carnica, the rest of the wings were identified as hybrids. Therefore the sample can- not be considered to belong to one of the Apis mellifera subspecies, but is a hybrid (see Figure 15);

-in Galati county, the samples from the three localities could not be classified as any subspecies, most wings expressing variable relatedness percentages to one of the subspecies, without it being possible to assess the type or level of hybridization (see Figure 16 to 20).

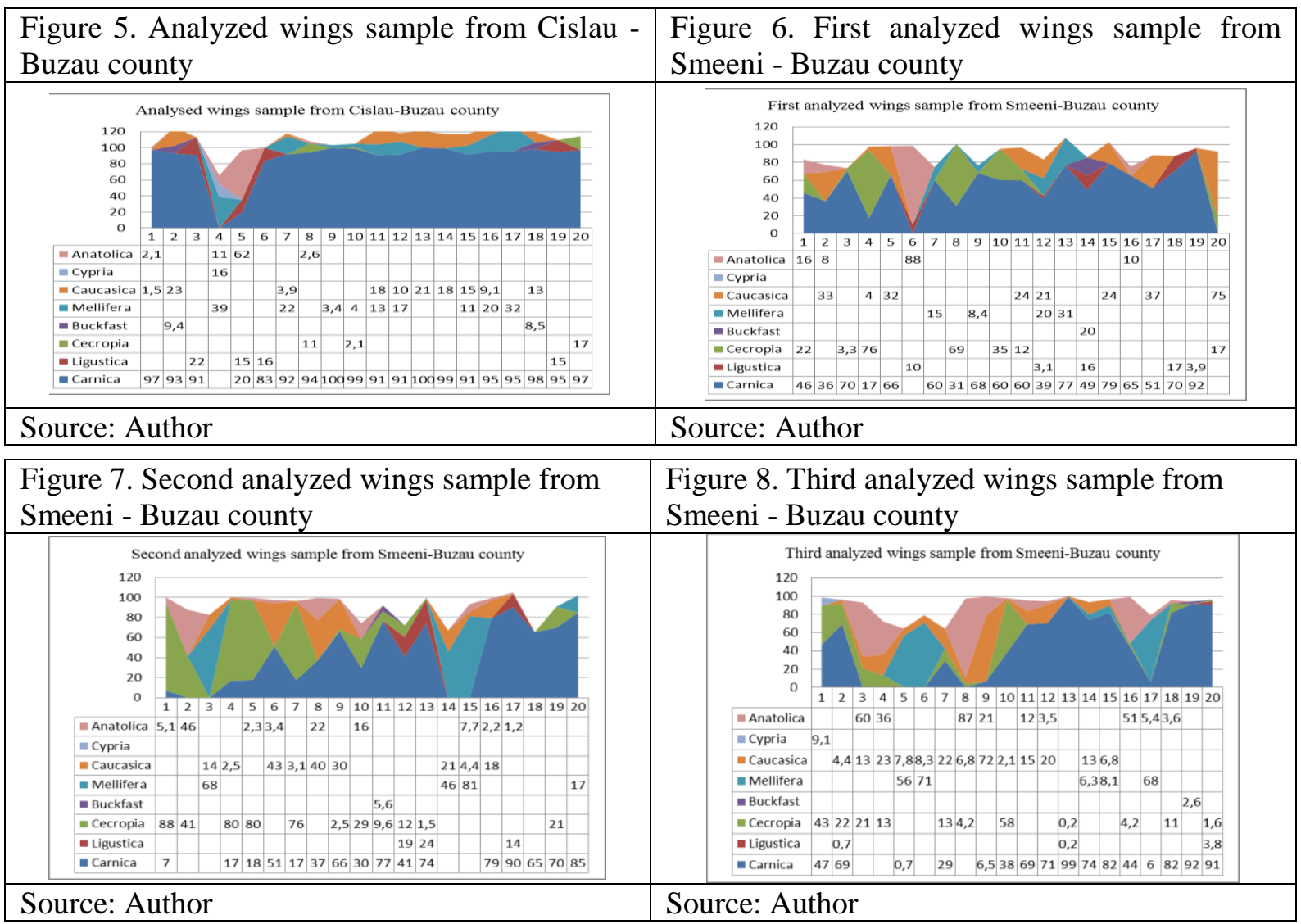




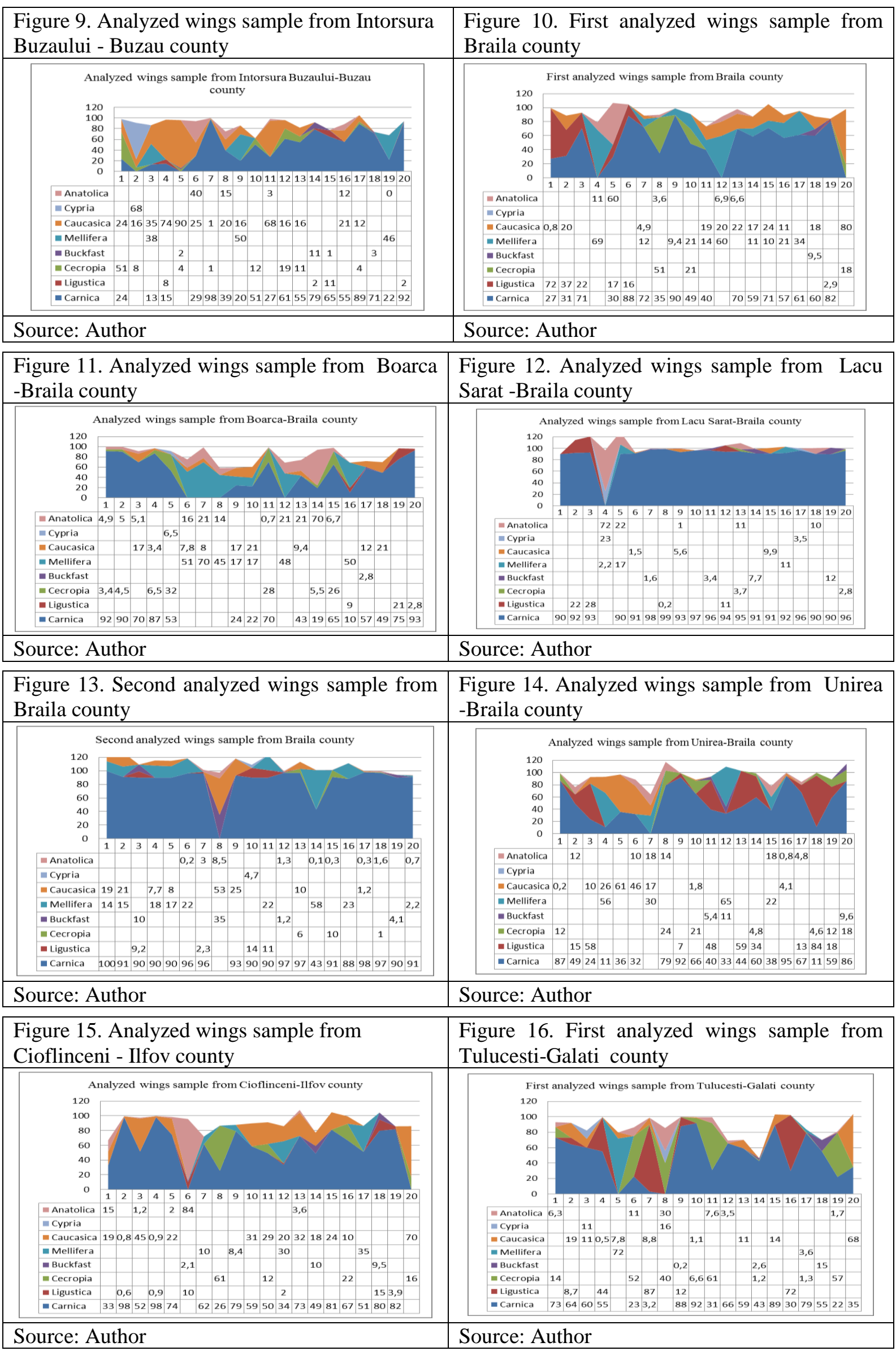




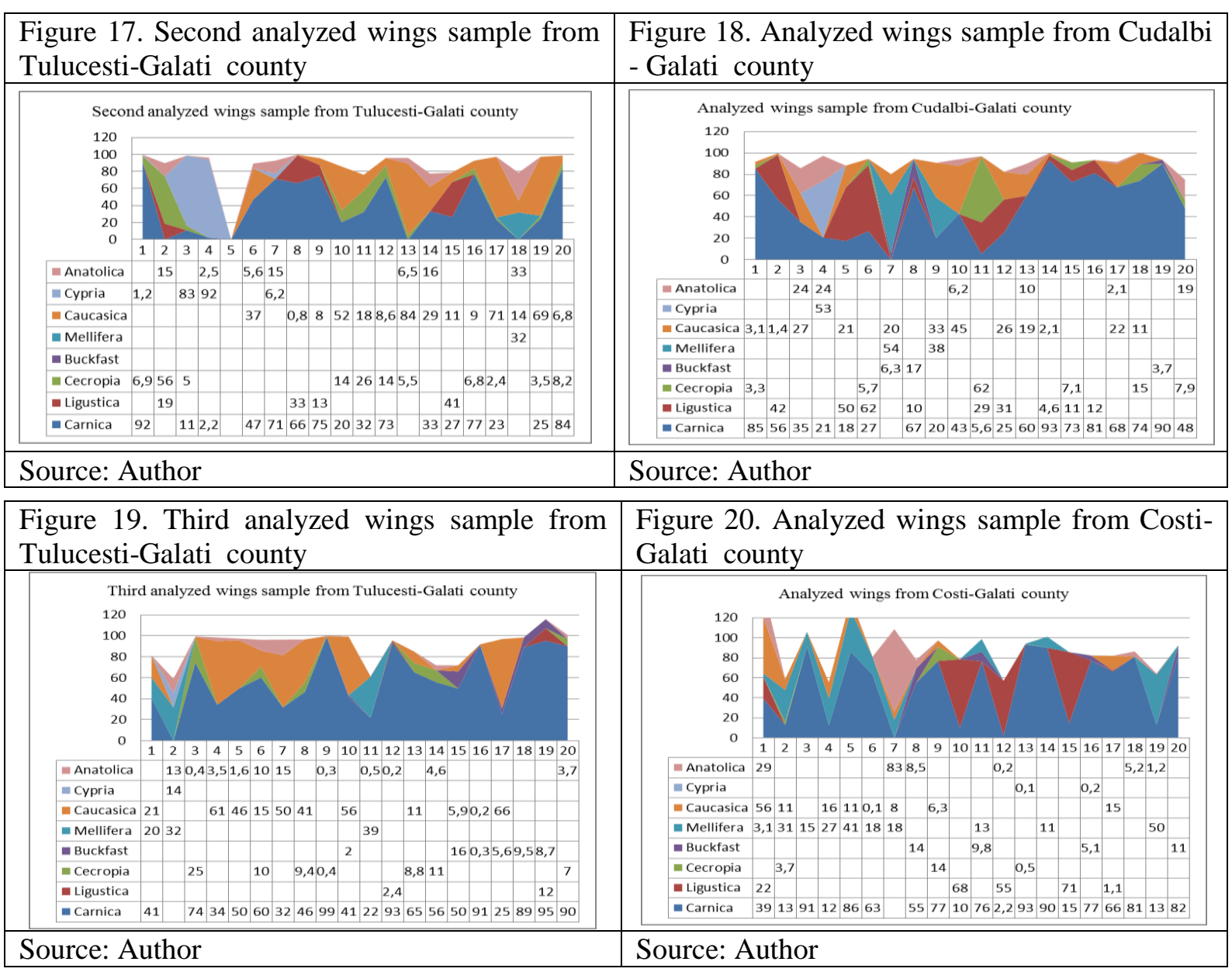

\section{Conclusion}

Based on the results of geometric morphometry upon the analyzed wings, the honey bee populations studied is polymorphic, being structured mainly from hybrids. Only three samplese were identified as being Apis mellifera carnica presenting a homology degree over $90 \%$ with the samples originating from Braila (Braila and Lacu Sarat) and Buzau (Cislau).

\section{References}

Baylac, M., Garnery, L., Tharavy, D., Pedraza-Acosta, J., Rortais, A., Arnold, G.(2008). ApiClass, an automatic wing morphometric expert system for honeybee identification. http://apiclass.mnhn.fr

Gerula, D., Tofilski, A., Węgrzynowicz, P., Skowronek, W.(2009). Computer-assisted discrimination of honeybee subspecies used for breeding in Poland. Journal of Apicultural Science, 53,105-114.

MacLeod, N., Warren, A., Culverhouse, P., Steinhage, V., Lampe, K., Uther, M., Wheeler, Q. (Ed.), Jones, D., Mortensen, E., Russell, K., Tofilski, A., Bookstein, F., Chesmore, D., Mendoza, M., O'Neill, M., Reyment, R., Clark, J., Knoll, M., Lang.R., Robert, V., Walsh, S., Cremers, A., Delgado, E., Deng, H., Dietterich, T., Do, M., Huff, J., Lytle, D., Paasch, R., Platnick, N., Purnell, M., Shapiro, L., Schroder, S., Wu, P., Zhang, W., Moldenke, A.(2007). Automated Taxon Identification in Systematics. CRC Press Taylor \& Francis Group, 289-300.

Nawrocka, A., Kandemir, I., Fuchs, S., Tofilski, A.(2017). Computer software for identification of honey bee subspecies and evolutionary lineages. Apidologie, 1-13. https://doi.org/10.1007/s13592-017-0538-y.

Oleksa, A., Tofilski, A.(2015). Wing geometric morphometrics and microsatellite analysis provide similar discrimination of honey bee subspecies.Apidologie, Springer Verlag, 46 (1), 49-60, 〈10.1007/s13592-014-0300-7〉 . 〈hal-01284421〉

Rinderer, T. E.(2008). Beegenetics and breeding. Northern Bee Books, 5-50.

Ruttner, F.(1988). Biogeography and Taxonomy of Honeybees. Springer-Verlag, 3-20.

Santana, F.S., Costa, A.H.R., Truzzi, F.S., Silva, F.L., Santos, S.L., Francoy, T.M., Saraiva, A.M.(2014, November). A reference process for automating bee species identification based on wing images and digital image processing. Ecological Informatics, 24, 248-260, https://doi.org/10.1016/j.ecoinf.2013.12.001.

Silva, F. L., Sella, M. L. G., Tiago, M. F., Reali Costa, A. H. (2015, June). Evaluating classification and feature selection techniques for honeybee subspecies identification using wing images. Computers and Electronics in Agriculture,114, 68-77, https://doi.org/10.1016/j.compag.2015.03.012.

Tofilski, A.(2008). Using geometric morphometrics and standard morphometry to discriminate three honeybee subspecies. Apidologie, 39 (5), 558-563, doi: 10.1051/apido:2008037. 